\title{
Evaluation of candidate polymers to maximize geotechnical performance of oil sands tailings
}

\author{
Ahlam Abdulnabi, Kwaku Amoako, Daniel Moran, Khushbu Vanadara, Abdulghader Abdulrahman Aldaeef, \\ Amin Esmaeilzadeh, Nicholas Beier, João Soares, and Paul Simms
}

\begin{abstract}
Oil sands fluid fine tailings deposits are challenging to reclaim due to their inherently high natural water content, low permeability, and low strength. Combinations of polymers and (or) coagulants are used by operators to improve the dewatering and strength properties of the tailings. However, considerably more work has been done to evaluate polymer performance with short-term dewatering metrics rather than with long-term metrics such as consolidation properties. This paper evaluates the potential of four novel polymers for use in fluid fine tailings treatment compared to a commercially available polymer and untreated tailings specimen. The performance of the polymers was assessed through initial screening with respect to short-term dewatering, evaluation of the consolidation and strength properties using large-strain consolidation tests, shear sensitivity in pipeline transport, and finally, large-strain consolidation modelling to appraise the relative potential performance under different strategies, such as terrestrial or aquatic reclamation options. One polymer exhibits remarkably fast dewatering at high void ratios, while another demonstrates dense and shear-resistant flocs. The paper discusses each polymer's distinctive tailings fabrics and how their unique merits and limitations would benefit different reclamation eventualities. Finally, potential improvements of the polymers are suggested for future assessment.
\end{abstract}

Key words: oil sands, tailings, polymers, consolidation, strength, modelling.

Résumé : Il est difficile de récupérer les dépôts de résidus fins fluides de sables bitumineux en raison de leur teneur naturelle en eau élevée, de leur faible perméabilité et de leur faible résistance. Pour améliorer les propriétés de déshydratation et de résistance des résidus, les exploitants utilisent des combinaisons de polymères et/ou de coagulants. Les performances des polymères ont toutefois été évaluées davantage en fonction de paramètres de déshydratation à court terme qu'en fonction de paramètres à long terme tels que les propriétés de consolidation. Le présent document évalue le potentiel de quatre nouveaux polymères pour une utilisation dans le traitement des résidus fins fluides par rapport à un polymère offert sure le marché et à un échantillon de résidus non traités. Les performances des polymères ont été évaluées par le biais d'une sélection initiale concernant la déshydratation à court terme, l'évaluation des propriétés de consolidation et de résistance à l'aide d'essais de consolidation à grande déformation, la sensibilité au cisaillement dans le transport par pipeline et, enfin, la modélisation de la consolidation à grande déformation pour évaluer les performances potentielles relatives dans le cadre de différentes stratégies, telles que les options de remise en état terrestre ou aquatique. Les résultats montrent qu'un polymère présente une déshydratation remarquablement rapide à des taux de vide élevés, tandis qu'un autre présente des flocs denses et résistants au cisaillement. L'article aborde les matériaux de résidus distinctifs de chaque polymère et la manière dont leurs mérites et limites uniques pourraient profiter à différentes éventualités de remise en état. Enfin, des améliorations potentielles des polymères sont suggérées pour une évaluation future. [Traduit par la Rédaction]

Mots-clés : sables bitumineux, résidus, polymères, consolidation, résistance, modélisation.

\section{Introduction}

Surface mining of oil sands bitumen deposits produce tailings, which comprise water, sands, clays, residual hydrocarbons, and chemicals originating from the bitumen extraction process (Royal Society of Canada Expert Panel 2010). While the sand fraction that settles out is relatively non-problematic, a significant proportion of the fines remains suspended in the water. These are referred to as fluid fine tailings (FFT). Some settling of solids occurs, but generally, after 3 to 5 years, a stable suspension $>200 \%$ gravimetric water content $(<35 \%$ solids by mass) persists, which thereafter exhibits little to no further settlement or

Received 17 November 2020. Accepted 12 May 2021.

A. Abdulnabi,* K. Amoako, and N. Beier. ${ }^{\dagger}$ Department of Civil and Environmental Engineering, University of Alberta, 7-207 Donadeo Innovation Centre for Engineering, Edmonton, Alberta, Canada, T6G 1H9.

D. Moran and J. Soares. Chemical and Materials Engineering Department, University of Alberta, Edmonton, Alberta, Canada.

K. Vanadara, A.A. Aldaeef, A. Esmaeilzadeh, and P. Simms. ${ }^{\dagger}$ Department of Civil and Environmental Engineering, Carleton University, Ottawa, Ontario, Canada.

Corresponding author: Ahlam Abdulnabi (email: aabdulnabi@thurber.ca).

*Present address: Thurber Engineering Ltd., Calgary, Alberta, Canada.

${ }^{\dagger}$ Nicholas Beier served as an Editorial Board Member and Paul Simms served as an Associate Editor at the time of manuscript review and acceptance; peer review and editorial decisions regarding this manuscript were handled by Behzad Fatahi.

(c) 2021 The Author(s). This work is licensed under a Creative Commons Attribution 4.0 International License (CC BY 4.0), which permits unrestricted use, distribution, and reproduction in any medium, provided the original author(s) and source are credited. 
consolidation over decades. This is attributed to various properties of the material, such as low hydraulic conductivity and formation of a gel structure that impedes consolidation (Suthaker and Scott 1997; Jeeravipoolvarn 2010). These tailings are typically deposited in dammed impoundments known as tailings ponds. As a consequence of the slow natural dewatering combined with the scale of the oil sands operations, these tailings ponds comprise some of the largest such deposits in the world. The total area of the tailings ponds is approaching $300 \mathrm{~km}^{2}$, with dam heights sometimes exceeding $80 \mathrm{~m}$ (COSIA 2014). For example, the Mildred lake settling basin, Alberta, Canada, with a circumference of $20 \mathrm{~km}$, is the largest tailings pond by area and volume in the world (U.S. Department of the Interior - Bureau of Reclamation 2015; available from https://www.usbr.gov/ (accessed 10 April 2020)).

Various environmental and geotechnical risks, as well as obligations to stakeholders, drive the need for reclamation of these ponds. The current regulation requires that all tailings ponds in operation be "ready-to-reclaim" within 10 years after mine closure, which means that the tailings deposits can be incorporated into either a terrestrial or an aquatic reclamation plan. For terrestrial landforms, this requires a tailings surface trafficable by heavy machinery and sufficient strength from top to bottom of the deposit to avoid a deep-seated slope stability failure (McKenna et al. 2016). This, in turn, implies achieving water contents close to the plastic limit, densities close to $70 \%$ solids, or post-peak undrained shear strengths of at least $25 \mathrm{kPa}$. This applies to deposits designed to mimic the slopes required to restore the natural topography of the surrounding boreal forest (McKenna et al. 2016). Aquatic reclamation refers to the re-deposition of tailings in the mined-out pits to form a substrate for self-sustaining "end pit lake" (CEMA 2012). This option requires that the tailings to be non-liquefiable and that consolidation slows down sufficiently to minimize the potential transport of contaminants to the surface, allowing the establishment of an unpolluted ecosystem in the overlying water body.

To improve dewatering performance, operators have adopted a combination of dewatering techniques including mechanical (inline mixing, centrifuge, thickeners), chemical amendments (flocculants and (or) coagulants) in conjunction with natural approaches (evaporation and freeze-thaw) to improve the dewatering and strength of the tailings. For terrestrial landforms, operators have trialled deep deposits of tailings and thin lifts deposits to employ natural processes such as evaporation and freeze-thaw in dewatering (Proskin et al. 2010; Qi et al. 2017b; Simms et al. 2019). While operators have had success in achieving more reclaimable deposits, considerable scope remains for optimizing these techniques.

Polymer flocculants have been used as a chemical treatment inline and within tank thickening processes to improve the settling and consolidation behaviour of FFT for many years (Sawatsky et al. 2018). Polymers used in FFT treatment are usually designed as a chain of monomers with a certain chemical composition, ionic charge (cationic, anionic, non-ionic, or amphoteric), structure (linear, branched, hyperbranched, or grafted), and molecular weight to achieve the desired flocculation performance (Vajihinejad et al. 2019).

Bench scale and field studies have demonstrated that amending FFT with polyacrylamide-based polymers decreases the bulk density and increases the hydraulic conductivity and undrained shear strength of FFT (Jeeravipoolvarn 2010; Yao 2012; Beier et al. 2013; Znidarčić et al. 2016; Wilson et al. 2018). Furthermore, polyacrylamide-based polymers with large molecular weights are effectively used in paste and thickened tailings (Mikula 2018). Flocculant dosage and mixing conditions impact the overall polymer performance and must be carefully optimized to attain the desired dewatering efficiency and performance goals (Yao et al. 2012; Znidarčić et al. 2016; Mikula 2018).

This paper focuses on the optimization of polymer design with respect to the geotechnical properties of tailings. Polymers are typically designed to enhance short-term dewatering in most types of deposits. Graduated column settling and capillary suction time (CST) are routinely used to assess the initial dewaterability of polymer amended FFT (Mikula and Freeman 2016; Gumfekar et al. 2019). Furthermore, turbidity, ion concentrations, total dissolved solids (TDS), and $\mathrm{pH}$ are regularly used to evaluate water quality (Vietti 2018). However, the long-term dewatering, dictated primarily by the consolidation properties of the tailings, may govern the overall performance, yet assessment of new polymers to dewater oil sands tailings that gives insight into these long-term processes is quite scarce. The design and assessment of four novel polymers compared to a conventional polymer used in the industry are presented. The potential comparative performance of the new tailingspolymer treatments is evaluated by a series of tests to improve the understanding of the relative long-term dewatering behaviour and the consolidation characteristics of the amended tailings.

The oil sands tailings literature is replete with studies comparing numerically-predicted long-term behaviour of tailings deposits based on laboratory-measured large-strain consolidation (LSC) parameters and field-scale pilots with differing levels of complexity, in particular, studies of polymer-flocculated FFT (Jeeravipoolvarn 2005, 2010; Jeeravipoolvarn et al. 2015; Qi et al. 2017a, 2020; among many others). These verification exercises demonstrate that finite strain consolidation modelling can predict the behaviour of polymeramended tailings deposits, with good agreement in the field for at least several years. Jeeravipoolvarn (2010) demonstrated that finite strain consolidation modelling is a suitable tool for estimating the settling behaviour of flocculated tailings when benchmarked against a validation standpipe. Likewise, Qi et al. (2017b) provided further support for LSC models, specifically UNSATCON, in capturing the behaviour not only in a highly-instrumented laboratory column test, but also with a $4.1 \mathrm{~m}$ deep field pilot.

This paper utilizes UNSATCON, which is a two-dimensional (2D) model that uses a piecewise-linear formulation virtually identical to CS2 (Fox and Berles 1997) for simulating large-strain consolidation in saturated materials, with the capacity to simulate sedimentation and multiple advanced formulations for coupling unsaturated behaviour. Relatively simple simulations incorporating only large-strain consolidation-sedimentation are presented as these analyses are intended only to evaluate the comparative performance of the polymers.

\section{Design of polymers}

The molecular architecture of polymer flocculants, as measured by their molecular weight distributions, chemical composition and (or) ionic charge distribution, and branching topology, is expected to affect their flocculation and dewatering performance (Vajihinejad et al. 2019; Gumfekar et al. 2019). This investigation contrasts the behaviour of four new polymer flocculants, amylopectin-graft-polyacrylamide (AP-g-PAM), hydroxypropyl methylcellulose-graft-polyacrylamide (HPMC-g-PAM), poly(vinylbenzyl trimethylammonium chloride) (P(VBTMAC)), and poly(vinylbenzyl trimethylammonium chloride-co-acrylamide) (P(VBTMAC-co-AM)) with clearly distinct molecular architectures (Fig. 1).

Figure 1 compares the molecular structures of all four polymers and illustrates the main polymer architecture details compared in this investigation: AP-g-PAM is a neutral graft co-polymer with a branched backbone, HPMC-g-PAM is a neutral graft co-polymer with a linear backbone, $\mathrm{P}(\mathrm{VBTMAC})$ is a linear cationic polymer in which all repeating units are cationic, and P(VBTMAC-co-AM) is a cationic co-polymer in which only 33\% repeating units are cationic.

The first two flocculants were composed of a natural backbone (AP-g-PAM: amylopectin, or HPMC-g-PAM: hydroxypropyl methylcellulose) and acrylamide grafts. Both flocculants had no ionic charges (neutral flocculants). In contrast, the latter two polymers were cationic. Flocculant P(VBTMAC) was a homopolymer of vinyl benzyl trimethylammonium chloride, while flocculant P(VBTMACco-AM) was a co-polymer of vinyl benzyl trimethylammonium chloride (33 $\mathrm{mol} \%$ ) and acrylamide $(67 \mathrm{~mol} \%)$. These flocculants were compared to a benchmark flocculant (FLOPAM), which comprised a 
Fig. 1. Molecular structures of AP-g-PAM, HPMC-g-PAM, P(VBTMAC), and P(VBTMAC-co-AM). [Colour online.]

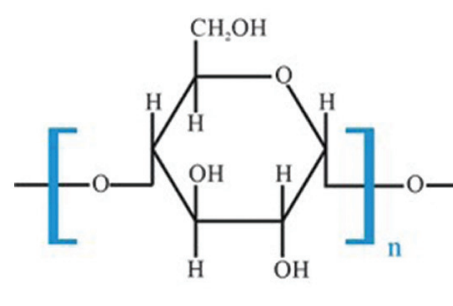<smiles>CC1C(CO)OCC(O)C1O</smiles>

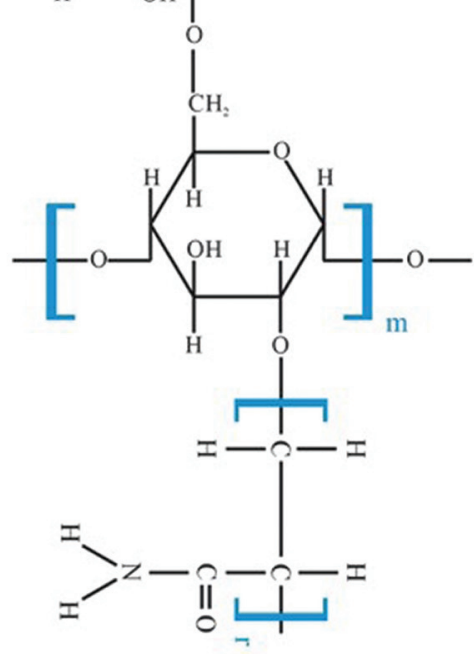<smiles>CC(C)C(c1ccc(C[N+](C)(C)C)cc1)C(C)(C)C</smiles>

P(VBTMAC)

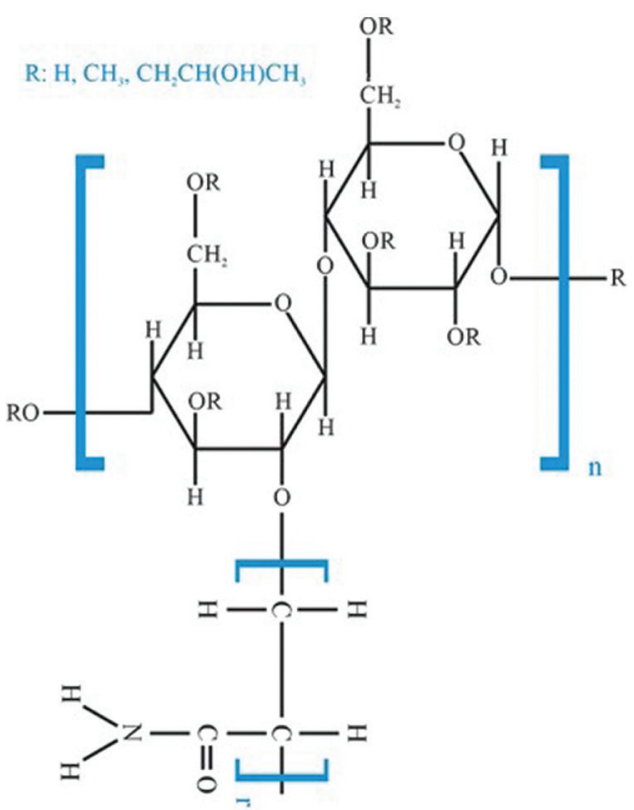

\section{HPMC- $g$-PAM}

Table 1. Novel polymers flocculants characteristics.

\begin{tabular}{llll}
\hline Designation & Polymer & Ionic charge & Comments \\
\hline AP-g-PAM & Amylopectin-graft-polyacrylamide & Neutral & Branched backbone \\
HPMC-g-PAM & Hydroxypropyl methylcellulose-graft-polyacrylamide & Neutral & Linear backbone \\
P(VBTMAC) & Poly(vinylbenzyl trimethylammonium chloride) & Cationic & Fully cationic homopolymer \\
P(VBTMAC-co-AM) & Poly(vinylbenzyl trimethylammonium chloride-co-acrylamide) & Cationic & 67 mol \% acrylamide \\
FLOPAM & A branched anionic polyacrylamide & Anionic & Commercial polymer flocculant known as A3338 \\
\hline
\end{tabular}

branched anionic polyacrylamide. Table 1 summarizes the chemical composition, ionic charge, and reference designations used to refer to these polymers throughout this paper.

Polyacrylamide is considered the standard flocculant for oil sands tailings. Therefore, acrylamide was used as the grafting monomer for two natural polymers with branched (AP-g-PAM) and linear (HPMC-gPAM) backbones. Synthesis details for flocculant AP-g-PAM are available in Bazoubandi and Soares (2020). Flocculant HPMC-g-PAM was synthesized following the same procedure, but by replacing amylopectin with hydroxypropyl methylcellulose. 
Cationic flocculants have been used less often to treat oil sands tailings, which may seem surprising at first sight because the clays suspended in tailings contain mostly anionic charges. While neutral polymers can interact with these clays via Van der Waals forces and hydrogen bonds, anionic polymers typically require a divalent cation to act as a bridge between the clay surface and the anionic polymer. A cationic polymer, on the contrary, in principle, would not require the presence (or addition) of cations.

The cationic monomer chosen to create the second set of flocculants has the additional advantage of being partially hydrophobic: vinyl benzyl trimethylammonium chloride contains hydrophobic pendant benzene rings that form a polymer that can be dissolved in water, but generates a floc matrix that retains less water than the conventional polyacrylamide. The poor dewatering of the floc matrix produced with polyacrylamide is a known limitation of this commercial flocculant. Therefore, with flocculant P(VBTMAC), there may be a twofold advantage: the cationic charges interact directly with the anionic clay surfaces, and the partially hydrophobic flocs retain less water and dewater more easily in short-term experiments quantified by CST measurements (Hripko et al. 2018; Vajihinejad 2020).

The cationic polymer P(VBTMAC) was synthesized following the procedures described in Vajihinejad (2020). The motivation behind making the co-polymer P(VBTMAC-co-AM), which substituted approximately $67 \mathrm{~mol} \%$ of the partially hydrophobic cationic monomer with acrylamide, was to find out how a decrease in cationic charge and hydrophobicity would alter the performance of this flocculant.

\section{Initial polymer screening}

The four polymers were sent to Carleton University, Ontario, Canada for initial evaluation through flocculation trials and several preliminary dewaterability tests. These include CST tests, graduated cylinder sedimentation tests, optical microscopy, and various rheological tests. The CST is a metric commonly used to assess the initial dewaterability and filterability of tailings (Mikula and Freeman 2016; Elias 2019). CST tests involve placing the tailings in an $18 \mathrm{~mm}$ diameter and $50 \mathrm{~mm}$ height column overlaying a filtered block with two electrodes. The reported CST time in seconds represents the time it takes for water to propagate between the two electrodes (approximately $6.5 \mathrm{~mm}$ distance). Therefore, the smaller the CST value, the faster the dewaterability. CST values for FFT treated with AP-g-PAM, HPMC-g-PAM, $\mathrm{P}(\mathrm{VBTMAC})$, and $\mathrm{P}(\mathrm{VBTMAC}-\mathrm{Co}-\mathrm{AM})$ were $70,100,20$, and $90 \mathrm{~s}$, respectively. All these polymers exhibited lower CST values, hence faster initial dewaterability, than the conventional FLOPAM, which results in a $280 \mathrm{~s}$ CST value when tested at optimum dose on the same FFT.

Furthermore, cylinder tests involve placing the tailings in a $100 \mathrm{~mL}$ cylinder with a $28 \mathrm{~mm}$ diameter to observe the settlement with time through monitoring the tailings' water interface as well as the clarity of supernatant water. Figure 2 illustrates the general dewatering behaviour of the treated tailings inferred from these tests. The suspended solids in the supernatant water for AP-g-PAM, HPMC-g-PAM, P(VBTMAC), and P(VBTMAC-co-AM) were $0.06,3.4,0.3$, and $0.3 \mathrm{~g} / \mathrm{L}$, respectively. Smaller values indicate better clarity of the supernatant water.

In terms of flocs structure, the neutral polymers (AP-g-PAM and HPMC-g-PAM) created flocs with a fibrous structure, whereas the cationic polymers $(\mathrm{P}(\mathrm{VBTMAC})$ and $\mathrm{P}(\mathrm{VBTMAC}-\mathrm{co}-\mathrm{AM}))$ generated smaller, distinct flocs with granular morphology. For the AP-gPAM treatment, flocs would often stick to the sides of the container in these small-scale tests.

In terms of net water release (NWR), both the cationic polymers released less water than the neutral polymers and exhibited poorer NWR in these tests. NWR was calculated by deducting the volume of hydrated polymer added to FFT during treatment from
Fig. 2. Initial dewatering behaviour of treated tailings in small, graduated cylinders. [Colour online.]

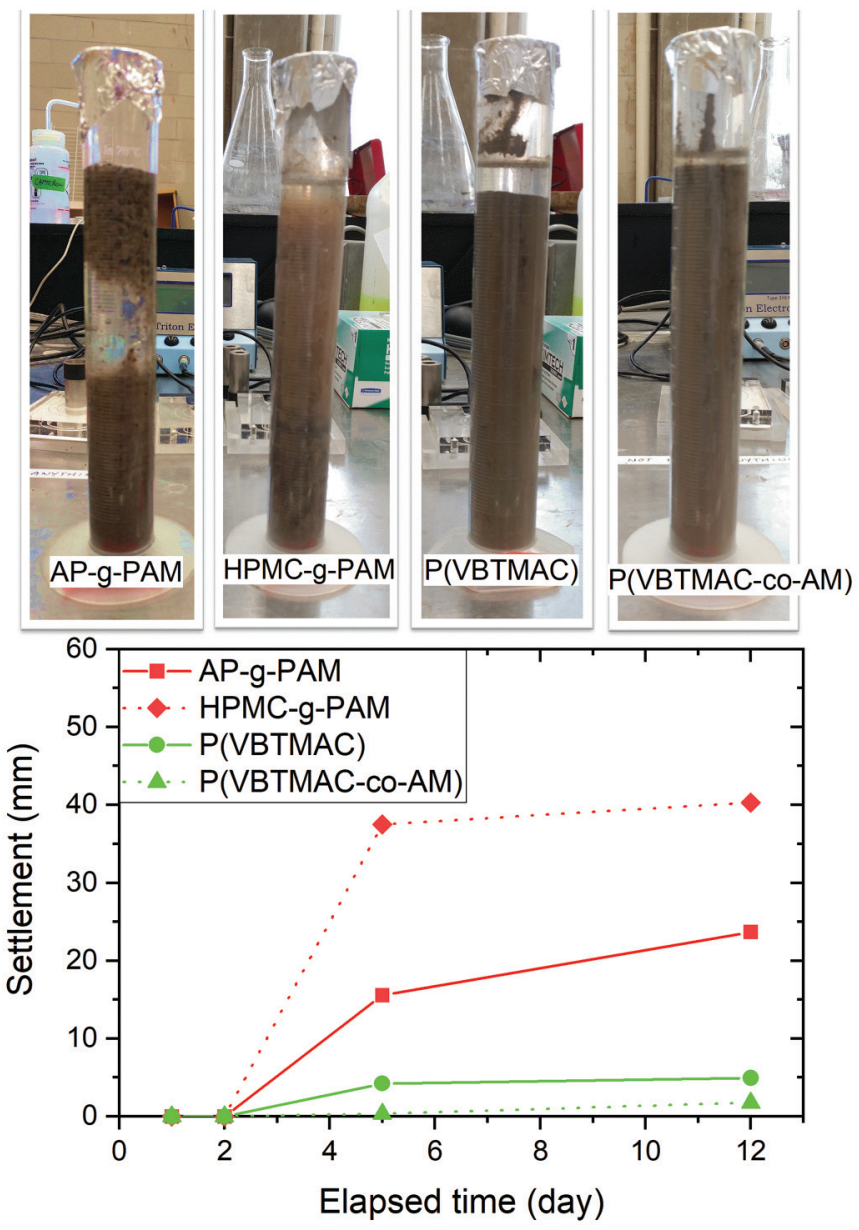

Table 2. Polymer solution concentrations and dosage.

\begin{tabular}{llll}
\hline Polymer & $\begin{array}{l}\text { Mass of polymer per } \\
500 \mathrm{~mL} \text { solution }(\mathrm{g})\end{array}$ & $\begin{array}{l}\text { Concentration } \\
(\%)\end{array}$ & $\begin{array}{l}\text { Treatment } \\
\text { dosage }(\mathrm{ppm})\end{array}$ \\
\hline AP-g-PAM & 1.0 & 0.2 & 8000 \\
P(VBTMAC) & 2.0 & 0.4 & 4000 \\
FLOPAM & 2.0 & 0.4 & 800 \\
\hline
\end{tabular}

the total volume of water released. None of the four treated tailings demonstrated positive NWR from these tests compared to tests on the conventional commercial FLOPAM known as A3338, which would typically give positive NWR.

Based on these initial screening tests, FFT treated with AP-g-PAM have superior separation of flocs, initial dewaterability, better clarity and volume of the supernatant water, lower CST, and much lower suspended solids compared to HPMC-g-PAM. So, among the two neutral polymers, only AP-g-PAM moved forward to the next round of long-term testing. Similarly, among the two cationic polymers, only P(VBTMAC) moved to the next phase of testing due to its surpassing $\mathrm{P}(\mathrm{VBTMAC}-\mathrm{Co}-\mathrm{AM})$ in all these initial metrics.

When comparing the neutral to cationic polymers, AP-g-PAM has the best dewatering in the graduated cylinders, whereas P(VBTMAC) has the lowest CST hence better potential filterability. Compared to conventional FLOPAM polymer, both AP-g-PAM and P(VBTMAC) polymers had inferior NWR, but superior CST. Further details about the distinct features of each of the polymers and their interactions with the FFT are available in Vandara (2018). Table 2 summarizes 
Table 3. Initial tailings properties and Atterberg limits.

\begin{tabular}{llllllll}
\hline & & & & \multicolumn{3}{l}{ Atterberg limits } \\
\cline { 6 - 8 } Material & $\begin{array}{l}\text { Initial solids } \\
\text { content }(\%)\end{array}$ & $\begin{array}{l}\text { Fines } \\
\text { content (\%) }\end{array}$ & $\begin{array}{l}\text { Sand-to-fines } \\
\text { ratio (SFR) }\end{array}$ & $\begin{array}{l}\text { Initial void } \\
\text { ratio }\end{array}$ & $\begin{array}{l}\text { Liquid } \\
\text { limit }\end{array}$ & $\begin{array}{l}\text { Plastic } \\
\text { limit }\end{array}$ & $\begin{array}{l}\text { Plasticity } \\
\text { index }\end{array}$ \\
\hline Untreated FFT & 30.5 & 94 & 0.06 & 5.17 & 52 & 30 & 22 \\
AP-g-PAM & 13.7 & $\mathrm{NM}$ & $\mathrm{NM}$ & 14.25 & 82 & 46 & 36 \\
P(VBTMAC) & 23.6 & 92 & 0.09 & 7.44 & 76 & 44 & 31 \\
FLOPAM & 28.9 & 72 & 0.39 & 5.63 & 78 & 39 & 38 \\
\hline
\end{tabular}

Note: NM, not measured.

the optimal dosages of polymer treatments and mixing times and durations, as was determined based on the flocculation trials.

\section{Geotechnical experimental testing of polymer amended FFT}

An experimental laboratory program was conducted to study the long-term dewatering performance of the FFT treated with the two candidate polymers selected to proceed to phase 2 of long-term testing. The reader is reminded that AP-g-PAM is a neutral polymer while $\mathrm{P}(\mathrm{VBTMAC})$ is a cationic polymer. These candidate polymers are compared to the commercially available anionic polyacrylamide, FLOPAM, and an untreated control specimen. For clarity, all data pertaining to the neutral polymertreated tailings sample, AP-g-PAM, are represented with red diamond markers and red series, whereas data from the cationic polymer-treated samples, $\mathrm{P}(\mathrm{VBTMAC})$, are identified by green triangle markers and green series throughout the manuscript. Tailings samples treated with the anionic polyacrylamide, FLOPAM, are represented with blue squares and blue series. Finally, the benchmark untreated FFT sample is shown as grey circles and grey series.

The large-strain consolidation behaviour of treated tailings was examined to determine the compressibility, hydraulic conductivity, and undrained shear strength of the different polymer amendments. In addition, the basic properties of the tailings were characterized to assess the geotechnical effect of the polymer treatments on FFT before and during consolidation.

Using untreated FFT as a control sample in the experiments, samples of the same FFT were flocculated using the FLOPAM, AP-g-PAM, and P(VBTMAC) polymers. For each polymer treatment, the appropriate mass of FFT was treated based on the solids content and the polymer dosages and mixing times shown in Table 2.

\section{Tailings characterization}

Geotechnical characterization tests were performed on homogenized untreated and polymer treated FFT following ASTM standards to determine the basic tailings properties, including particle-size distribution (ASTM 2017a, standard D7928) and Atterberg limits (ASTM 2017b, standard D4318). Table 3 presents the initial properties of FFT before and after flocculation. The original FFT had a solids content of $30.5 \%$ and bitumen content of $2.4 \%$, an initial void ratio of 5.17 and a specific gravity of 2.27 . Further details on the characteristics of each treatment are available in Amoako (2020).

The particle-size distribution of the treated and untreated FFT (bitumen included) analyzed using the hydrometer test method (ASTM 2007, 2017a) is shown in Fig. 3. The treated tailings were analyzed without adding a dispersant, while FFT was examined under dispersed and non-dispersed conditions. In both conditions, the fines content $(<44 \mu \mathrm{m})$ and the dispersed clay-sized fraction $(<2 \mu \mathrm{m})$ of the FFT were approximately $94 \%$ and $40 \%$ by mass, respectively, indicating a sand-fines ratio (SFR) of 0.06 . The fines content and SFR of the P(VBTMAC) and FLOPAM treated FFT are provided in Table 3 . The $\mathrm{P}(\mathrm{VBTMAC})$ polymer appears to have
Fig. 3. (a) Particle-size distribution of tailings: dispersed and non-dispersed FFT; non-dispersed polymer-treated FFT and (b) plasticity chart of FFT. [Colour online.]
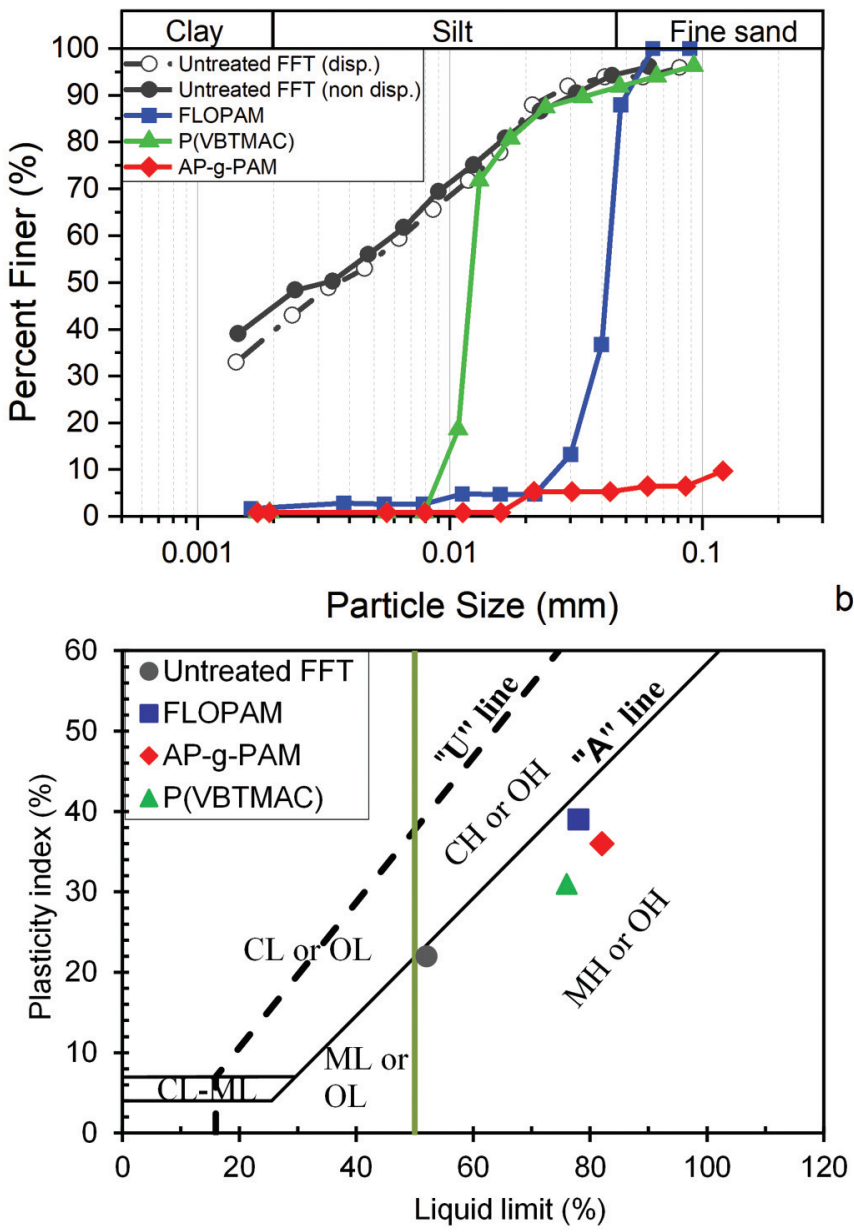

aggregated particles finer than $11 \mu \mathrm{m}$, whereas the average floc size of the FLOPAM treated FFT was about $40 \mu \mathrm{m}$. The floc sizes of the AP-g-PAM treated FFT were much larger, and the hydrometer measured only the approximate sizes of fine suspended flocs.

The Atterberg limits of the tailings were determined as per the ASTM (2017b) standard D4318-17, and the results are provided in Table 3. The untreated FFT had a liquid limit of $52 \%$ and a plasticity index of $22 \%$. The FLOPAM, AP-g-PAM, and P(VBTMAC) polymer treatments of FFT resulted in higher liquid limits and plasticity indices. The plasticity chart in Fig. $3 b$ shows reduced plasticity in the treated FFT with an evident increase in the liquid limit and plastic limit of FFT as a result of the polymer treatments. 
Fig. 4. Void ratio-effective stress relationships for untreated and polymer amended FFT. [Colour online.]

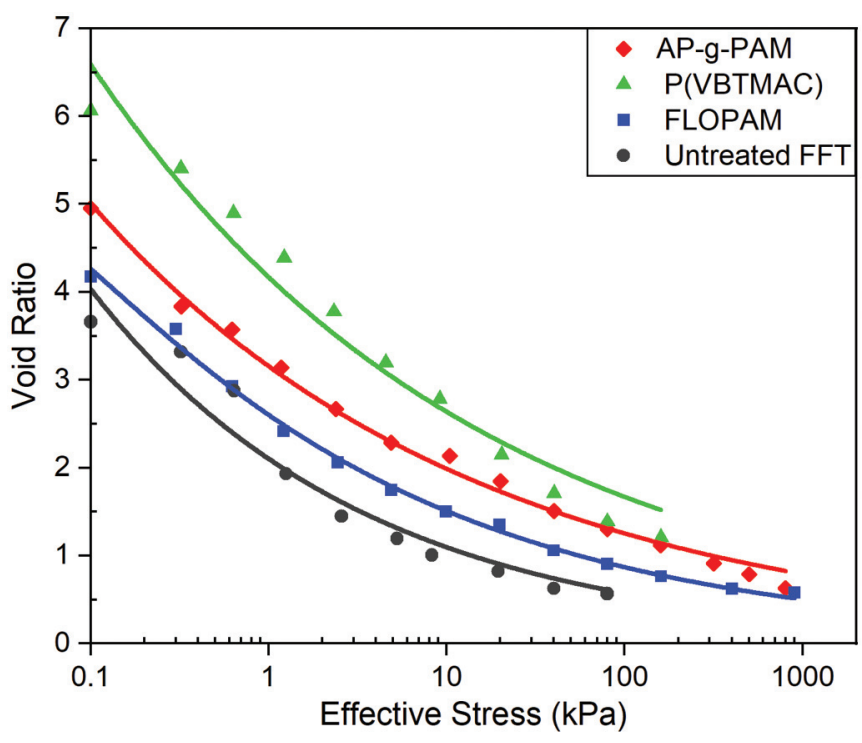

Large-strain consolidation test

The consolidation properties of the untreated and polymertreated FFT were studied in single-drainage large-strain consolidation tests. For each type of flocculated FFT, both original (S1) and duplicate (S2) samples were analyzed along with untreated FFT as a control sample. Homogenized treated and untreated FFT samples were poured into standard $200 \mathrm{~mm}$ high by $150 \mathrm{~mm}$ diameter LSC Plexiglas cells with a porous stone at the base, overlaid with a filter paper (pore size of $0.2 \mu \mathrm{m}$ ). The samples were allowed to settle and consolidate under self-weight, which corresponds to an average effective stress of $0.1 \mathrm{kPa}$ for these samples. Following the self-weight settlement, the consolidation of each sample was quantified by a multi-step loading scheme, where a known load is applied to the sample, and the deformation is directly measured. Once both excess pore pressure had entirely dissipated and vertical deformation was infinitesimal, consolidation was considered completed for a load step. At the end of each load step, the saturated hydraulic conductivity was measured by means of constant head test per ASTM (2019) standard D2434. Further details on large-strain consolidation standard procedures can be found in Jeeravipoolvarn (2010).

\section{Compressibility}

The effect of the polymer treatments on the compressibility of FFT was examined from the consolidation settlements of the tailings samples. The void ratio of the tailings at a given effective stress was determined from the measured deformation at the end of consolidation. Figure 4 illustrates the void ratio to effective stress relationship, which describes the compressibility of the tested samples. The compressibility constitutive relationship is seen in eq. 1. Fitting parameters for compressibility constitutive relationship are presented later, in the section titled "Consolidation modelling of hypothetical reclamation scenarios”.

$$
\text { (1) } e=A \sigma^{\prime B}
$$

where $A$ is the compressibility fitting parameter, $e$ is the void ratio, $\sigma^{\prime}$ is the effective vertical stress, $B$ is the compressibility fitting parameter.

Within $10 \mathrm{~h}$ following treatment, the void ratio of the AP-g-PAM treated FFT decreased from an initial 14.25 to 4.95 (31\% solids) under self-weight, with no further settlement observed. Similarly, the $\mathrm{P}(\mathrm{VBTMAC})$ and FLOPAM treated FFT settled to a void ratio of
Table 4. Large-strain consolidation time.

\begin{tabular}{llll}
\hline Treatment & $\begin{array}{l}\text { Range of effective } \\
\text { stress }(\mathrm{kPa})\end{array}$ & $\begin{array}{l}\text { Final void } \\
\text { ratio }\end{array}$ & $\begin{array}{l}\text { Total consolidation } \\
\text { time (weeks) }\end{array}$ \\
\hline Untreated FFT & $0-80$ & 0.56 & 51 \\
AP-g-PAM & $0-900$ & 0.63 & 17 \\
P(VBTMAC) & $0-900$ & 0.70 & 26 \\
FLOPAM & $0-900$ & 0.58 & 44 \\
\hline
\end{tabular}

6.06 (27\% solids) within 11 days and 4.17 (35\% solids) after 47 days, respectively. Conversely, the untreated FFT attained a void ratio of 3.66 (38\% solids) after 56 days. The larger part of the self-weight consolidation was dominated by the hindered settlement of particles in suspension at different rates based on particle/floc sizes in each treatment. The change in the void ratio of the tailings after self-weight consolidation indicates the amount of initial water released.

Table 4 presents the total large-strain consolidation time of all considered tailings. With incremental effective stresses from $0.3 \mathrm{kPa}$ to approximately $900 \mathrm{kPa}$, a final void ratio of $1.20(65 \%$ solids) was achieved in the P(VBTMAC) treated FFT at $160 \mathrm{kPa}$, after which no further compression was observed. The AP-g-PAM and FLOPAM treated FFT had final void ratios of 0.63 (78\% solids) and 0.58 (80\% solids), respectively. Table 4 indicates that both new polymer treatments significantly reduced the experimental consolidation time of FFT compared to the commercial FLOPAM treated FFT.

\section{Saturated hydraulic conductivity}

The measured saturated hydraulic conductivities were analyzed in relation to the changing void ratio of the various tailings. Figure 5 shows the hydraulic conductivities of the different tailings as a function of the void ratio. The hydraulic conductivity at a given void ratio was averaged for five to 10 measurements with a coefficient of variation ranging between 0.02 and 0.23 .

Over the range of effective stresses analyzed, the average hydraulic conductivity decreased by about four orders of magnitude for the P(VBTMAC) and FLOPAM treated FFT, and five to six orders of magnitude for the AP-g-PAM treated FFT. The lowest hydraulic conductivity was recorded in the untreated FFT at the end of the self-weight consolidation phase at a void ratio of 5 . Figure 5 shows that at void ratios greater than 3.8, where effective stresses are low, the hydraulic conductivity of the AP-g-PAM treated FFT was one order of magnitude higher compared to all other treatments. This is attributed to higher fluid flow through the pore spaces between the large flocs. The P(VBTMAC) and FLOPAM treated FFT exhibited somewhat similar hydraulic conductivities within experimental error at void ratios higher than 2.8. At effective stresses higher than $0.3 \mathrm{kPa}$ where void ratios were below 3.8 , the hydraulic conductivity of the AP-g-PAM treated FFT significantly reduced by about two orders of magnitude to rates close to that of the FLOPAM treated FFT. This sudden reduction in the hydraulic conductivity is due to the collapse of the large pores due to floc compression under increased load, forcing fluid flow through the floc microstructure. In the long-term where void ratios are considerably low, the hydraulic conductivity of the $\mathrm{P}(\mathrm{VBTMAC})$ treated FFT is three times higher compared to the other treatments. The hydraulic conductivity constitutive relationship is seen in eq. 2. Fitting parameters for the saturated hydraulic conductivity constitutive relationship are presented in Table 4 .

(2) $\quad k=C e^{D}$

where $k$ is the coefficient of saturated hydraulic conductivity, $C$ is the hydraulic conductivity fit parameter, $D$ is the hydraulic conductivity fit parameter. 
Fig. 5. Hydraulic conductivity-void ratio relationships of untreated and polymer amended FFT. [Colour online.]

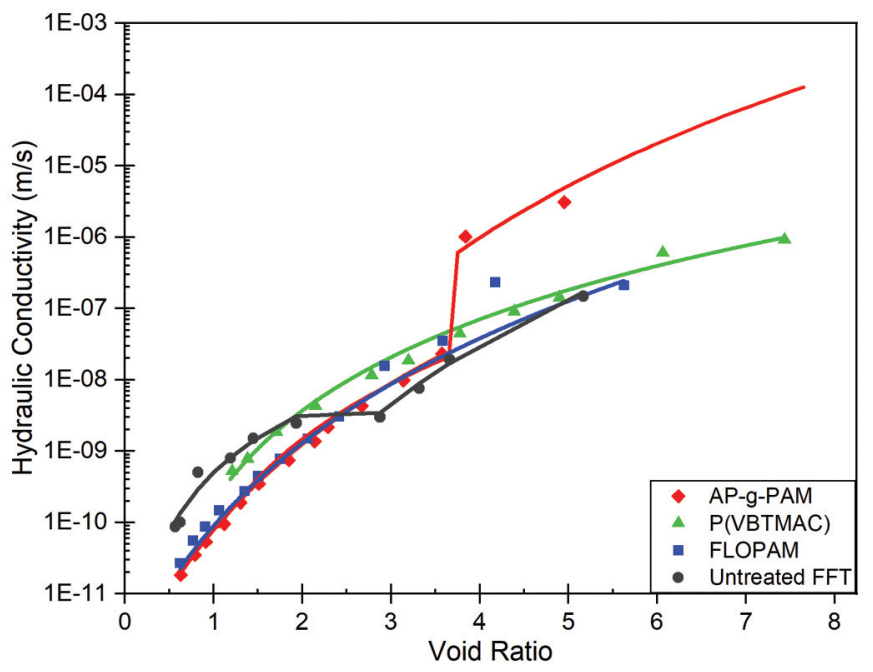

\section{Shear strength}

Undrained shear strength measurements were limited to the peak undrained shear strength to minimize floc disturbance. Soft consistencies (less than $8 \mathrm{kPa}$ ) were analyzed using a Brookfield DV3T rheometer to obtain the peak yield stress at a shearing rate of $0.1 \mathrm{rpm}$, while a motorized laboratory vane shear apparatus with standard vane sizes and torque springs was used for testing stiffer consistencies per ASTM (2016) standard D4648.

The undrained shear strength produced by each polymer treatment as a function of the solids content is illustrated in Fig. $6 a$, where the error bars indicate the range of shear strengths from two to three measurements. The results indicate that, at a given solids content, the undrained shear strength achieved in both the AP-g-PAM and P(VBTMAC) treated FFT is significantly higher than that of the FLOPAM PT. The new polymers increase the shear strength of FFT by more than two orders of magnitude. Below a solids content of $40 \%$, the undrained shear strength of the AP-gPAM treated FFT is about three times higher compared to the $\mathrm{P}(\mathrm{VBTMAC})$ treated FFT. This may be attributed to the distinct floc structure created by the AP-g-PAM polymer after treatment.

The undrained strength was then normalized with respect to vertical effective stress $\left(S_{\mathrm{u}} / \sigma^{\prime}\right)$ and evaluated a function of the total void ratio, as seen in Fig. $6 b$. The trends shown in this figure suggest that the peak strength is dominated by non-frictional effects. Furthermore, both AP-g-PAM and FLOPAM treated FFT provide higher strength ratios at a low void ratio, unlike the $\mathrm{P}(\mathrm{VBTMAC})$ treated FFT. Furthermore, all trends, including the untreated, seem to converge at both $S_{\mathrm{u}} / \sigma^{\prime}$ and void ratio of 0.5 .

\section{Shear sensitivity}

Shear sensitivity during pipeline transport is evaluated using a specialized Couette rheometer designed to simulate levels of shearing encountered during hydraulic transport (Derakhshandeh et al. 2016; Aldaeef and Simms 2019). The Couette consists of an outer stationary cylinder (cup) and inner cylinder (bobbin) and rotates at a controlled revolving speed. The height of the cup and the bobbin are 150 and $110 \mathrm{~mm}$, respectively. The diameters of the cup and the bobbin, including the baffles, are 118 and $76 \mathrm{~mm}$, respectively. In Fig. 7, the treated tailings are sheared at a rate corresponding to a pipe diameter of $762 \mathrm{~mm}$ and a mean velocity of $1.61 \mathrm{~m} / \mathrm{s}$. The change in the tailings properties is evaluated by changing the torque or resistance to flow and the CST. Both in absolute and relative terms, the $\mathrm{P}(\mathrm{VBTMAC})$ polymer appears to generate tailings of relatively low sensitivity to shear, as the ratio
Fig. 6. (a) Peak undrained shear strength-solids content relationships of untreated and polymer amended FFT, and $(b)$ peak undrained shear strength-effective stress relationships of untreated and polymer amended FFT. [Colour online.]
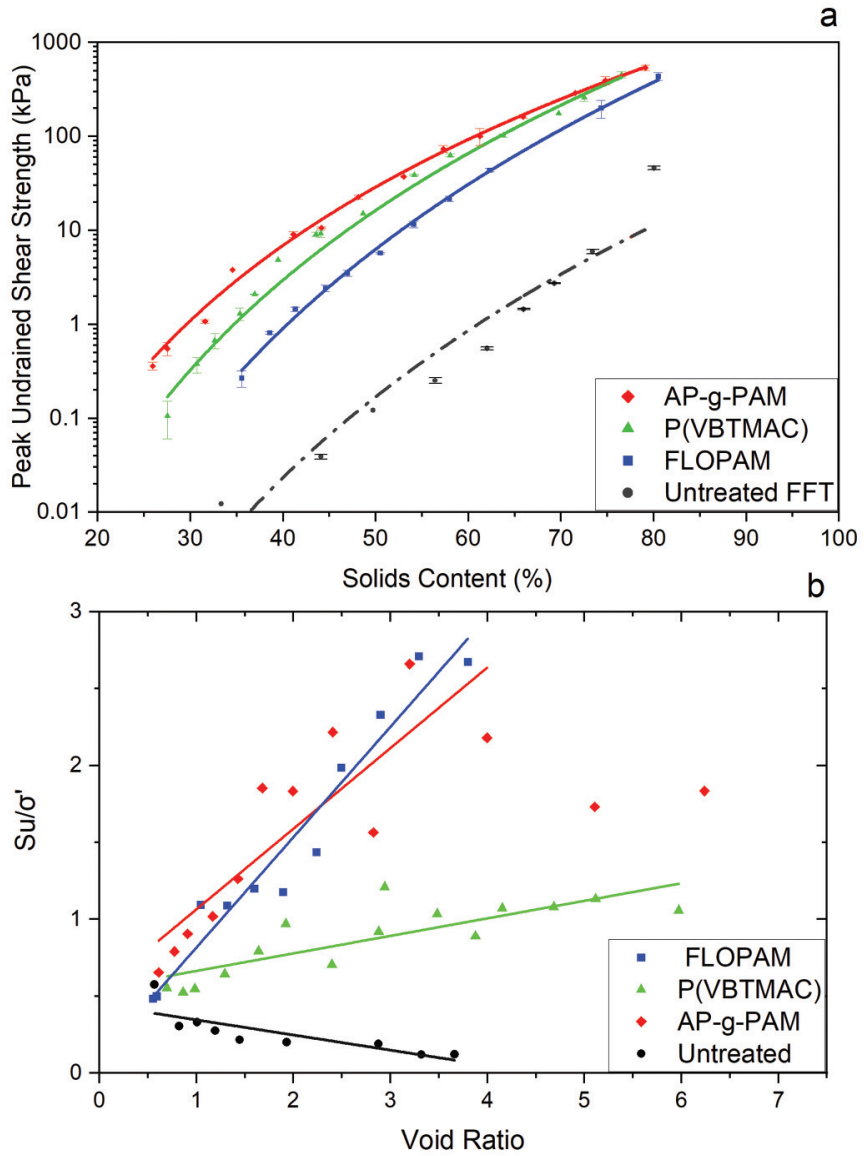

of CST before and after shearing (1.8), and the final absolute CST (37 s) are quite low.

\section{Consolidation modelling of hypothetical reclamation scenarios}

To illustrate the long-term performance of the different treatments, both terrestrial and aquatic hypothetical reclamation scenarios were assessed using a large-strain consolidation-sedimentation model. The quantity of FFT was estimated based on a hypothetical mine producing 200000 barrels of bitumen a day, assuming a bitumen content in the minable oil sands of $10 \%$, a fines content of $20 \%$, and fine capture within the sand fraction of tailings of $45 \%$. This theoretical operation would produce FFT with a mass of solids of $130000 \mathrm{t} /$ day and 47.5 million t/year. These estimates were in line with typical values from current mining operations near Fort McMurray, located in northeast Alberta, Canada, in the middle of the Athabasca oil sands. These typical values are summarized in an overview of tailings planning report to Canada's Oil Sands Innovation Alliance (COSIA) by Norwest Corporation (McKinley et al. 2018).

Sixteen deposition scenarios in total were considered using the AP-g-PAM, P(VBTMAC), and FLOPAM polymers treatments and untreated FFT assuming 5 and $10 \mathrm{~km}^{2}$ tailings impoundment footprints for both terrestrial and aquatic schemes. For the terrestrial reclamation option, the treated tailings were assumed to be deposited at the same rate that FFT is generated during the 40 year mine life then quiesce for 60 more years. For the aquatic option, the same mass of solids of legacy tailings generated 
Fig. 7. Relative shear sensitivity of treated tailings. [Colour online.]

a. AP-g-PAM

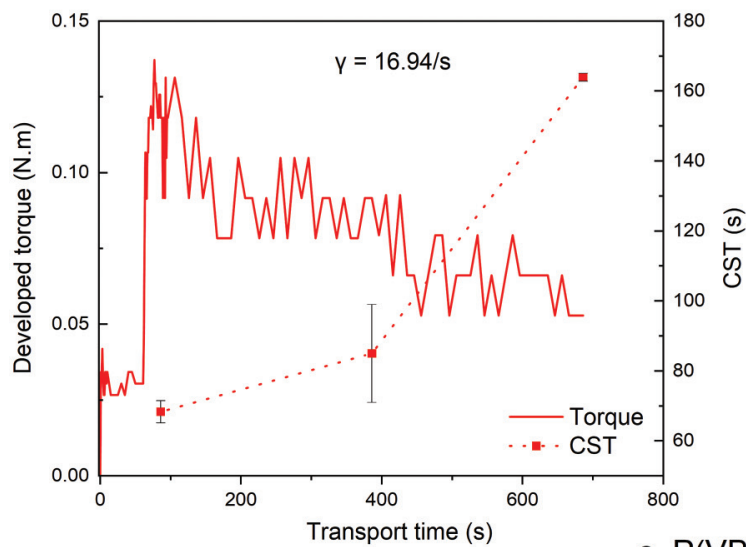

b. FLOPAM

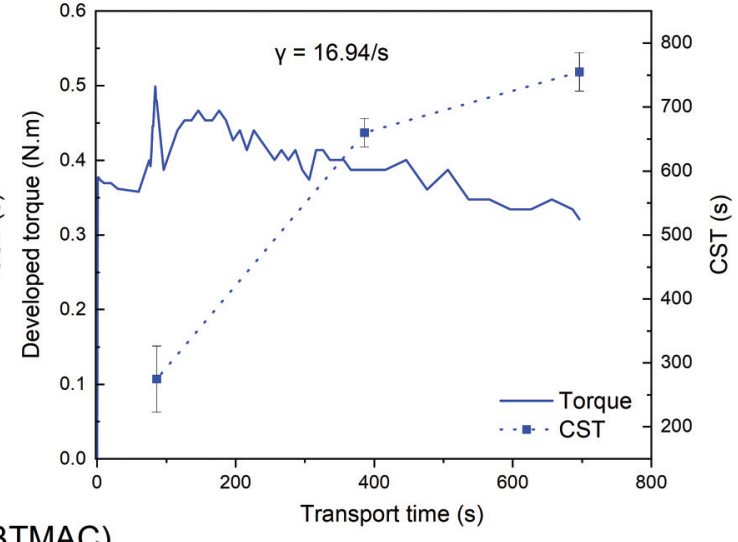

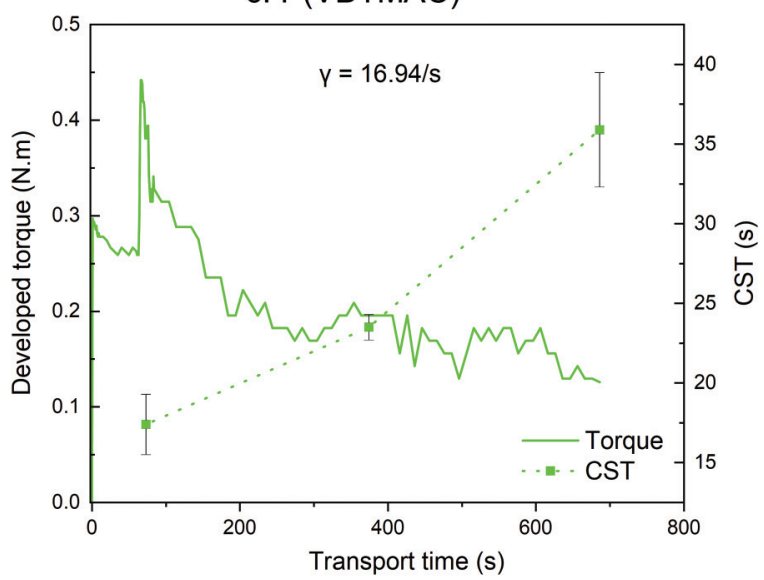

Table 5. Initial conditions of tailings deposits associated with terrestrial and aquatic depositions of tailings ponds of 5 and $10 \mathrm{~km}^{2}$.

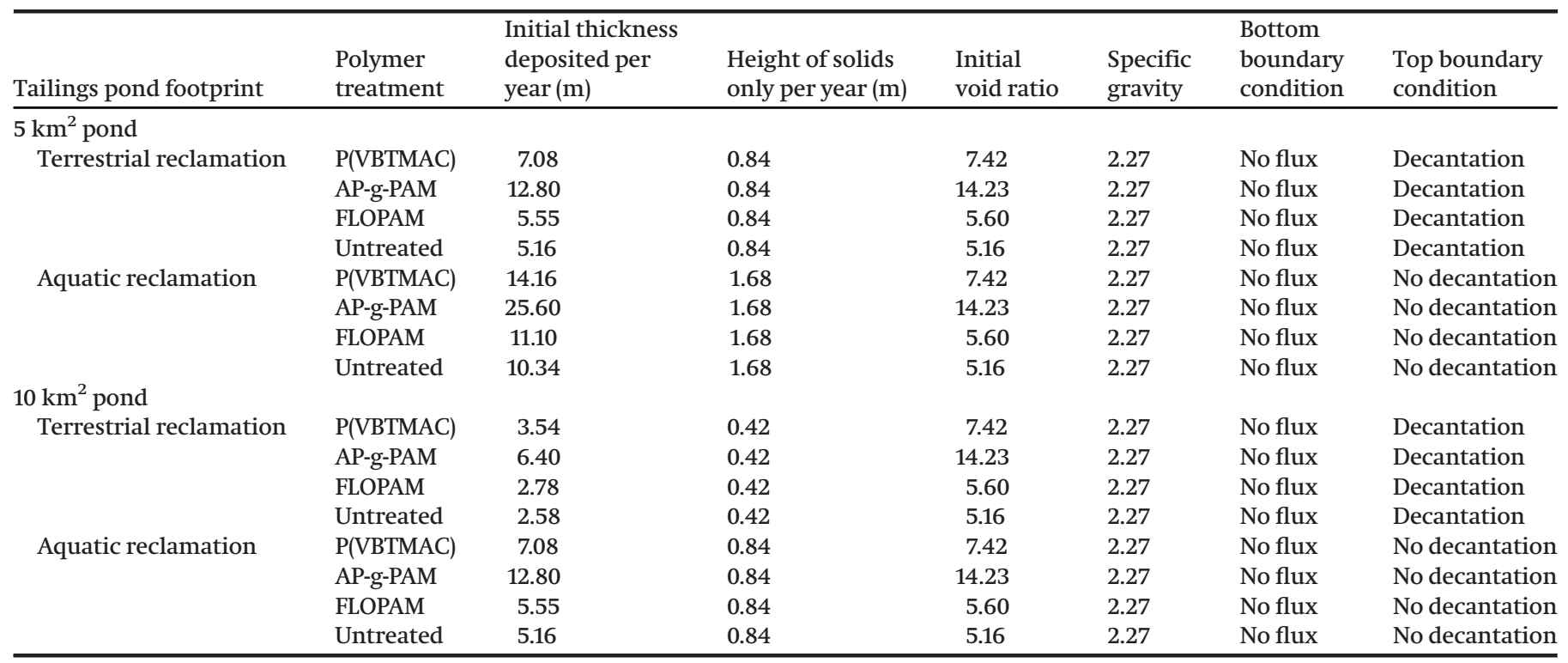

over 40 years was assumed to be treated and re-deposited over 20 years. This short deposition time is desirable to establish quiescent conditions favourable to ecosystem restoration quickly. Table 5 shows the respective initial void ratios and rates of rise for each treated and untreated tailings setting.
The hypothetical deposits were simulated using the large-strain consolidation software UNSATCON (Qi et al. 2017a, 2017b, 2020). UNSATCON is a 2D model that uses a piecewise-linear formulation virtually identical to CS2 (Fox and Berles 1997) for simulating largestrain consolidation in saturated materials, with the capacity to 
Table 6. Compressibility and hydraulic conductivity constitutive relationships used as numerical input.

\begin{tabular}{lll}
\hline Treatment & Compressibility & Hydraulic conductivity versus void ratio \\
\hline Untreated FFT & $e=2.103 \sigma^{\prime-0.28}$ & $k=3 \mathrm{E}-12 e^{6.7}(e \geq 2.876)$ \\
& & $k=3 \mathrm{E}-10 e+2.5 \mathrm{E}-9(1.93<e<2.876)$ \\
& $k=5 \mathrm{E}-10 e^{2.8}(e \leq 1.93)$ \\
AP-g-PAM & $e=3.15 \sigma^{\prime-0.201}$ & $k=3 \mathrm{E}-11 e^{7.5}(e \geq 3.7)$ \\
& & $k=7 \mathrm{E}-11 e^{4.4}(e<3.7)$ \\
P(VBTMAC) & $e=5.04\left(\sigma^{\prime}+0.434\right)^{-0.28}$ & $k=5 \mathrm{E}-10\left(e^{5}\right) /(1+e)$ \\
FLOPAM & $e=2.8 \sigma^{\prime-0.284}$ & $k=4 \mathrm{E}-11 e^{5}$ \\
\hline
\end{tabular}

Fig. 8. (a) Height of tailings-water interface versus time, (b) settlement versus time, and (c) top flux versus time for terrestrial reclamation cases for tailings disposal areas of $5 \mathrm{~km}^{2}$ (solid lines) and $10 \mathrm{~km}^{2}$ (dashed lines). [Colour online.]

a. Interface

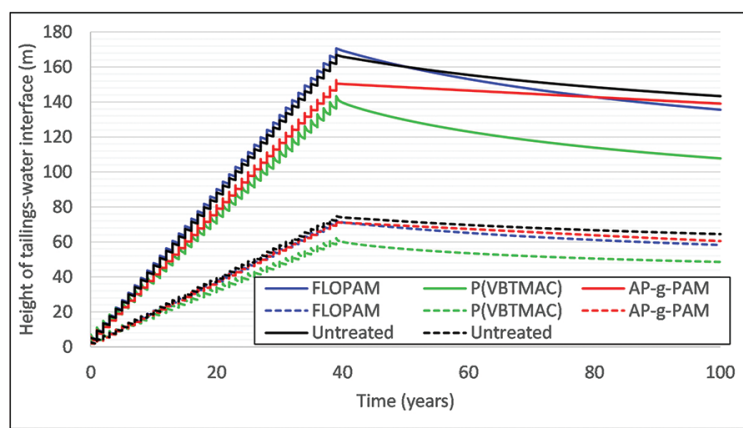

b. Settlement

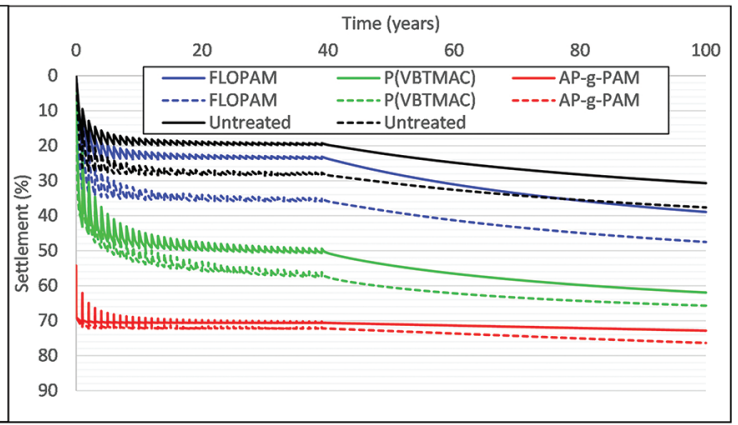

\section{c. Top flux}

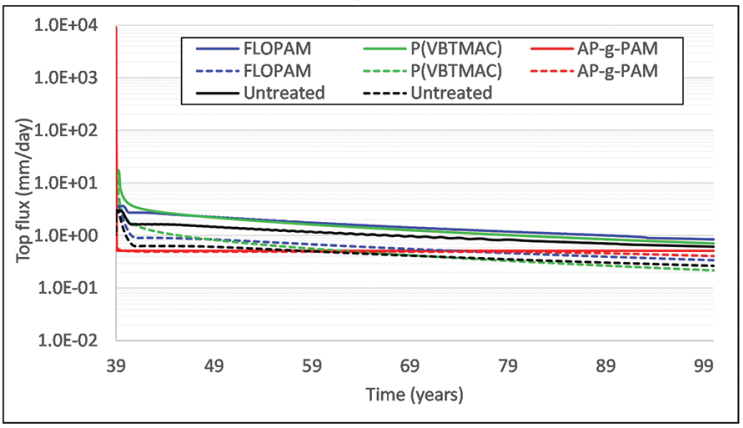

simulate sedimentation and multiple advanced formulations for coupling unsaturated behaviour. Relatively simple simulations incorporating only large-strain consolidation-sedimentation are presented as these analyses are intended only to evaluate the comparative performance of the polymers. For example, the terrestrial landscape would likely benefit from drying and (or) freeze-thaw effects, but these are not considered. Nor are time-dependent effects such as creep and ageing, which may influence the performance of certain types of treated tailings (Salam et al. 2018; Salam 2020).

Sedimentation and consolidation phenomena are coupled in the UNSATCON model by specifying a void ratio as a transition void ratio from the sedimentation state to the consolidation state. The effective stress at any void ratio larger than the transition void ratio is equal to zero, while the effective stress at void ratios smaller than the transition void ratio is calculated from the void ratio-effective stress equation. It should be noted that the transition from sedimentation state to consolidation state occurs at a specific void ratio (transition void ratio) in UNSATCON, while other models employ transition zones (for example, Jeerivapoolvarn et al. 2009). The value of the transition void ratio used in these numerical simulations is taken from the void ratio measured at $0.1 \mathrm{kPa}$ in the large-strain consolidation tests (Fig. 4). There is no numerical requirement for a smoothing function between the two states in UNSATCON due to its formulation.

The model inputs required for the numerical analyses are given in Table 5 . The compressibility and hydraulic conductivity $k-e$ equations used in modelling these treatment behaviours numerically are also presented in Table 6. For the FLOPAM and P(VBTMAC) treated FFT, the typical power-law relations were assumed for the $k-e$ function, while an S-shaped fit was adopted for the $k-e$ function for the AP-gPAM treated FFT, which shows a distinct behaviour at high void ratios (Fig. 4). The bottom boundary is no-flux; the top boundary assumes decantation, but no evaporation for the terrestrial deposition cases, whereas no decantation is assumed for the aquatic deposition cases. Modelling results using these functions are sensitive to the $k-e$ function, and using a conventional power type function for the AP-g-PAM treated FFT generates quite different results.

\section{Results of reclamation case analyses}

\section{Terrestrial reclamation}

The results of terrestrial reclamation cases are shown in Figs. 8 and 9 , where the settlement of the 5 and $10 \mathrm{~km}^{2}$ tailings ponds are shown as solid lines and dashed lines, respectively. The P(VBTMAC) treated FFT show the lowest height at any time after the end of the 
Fig. 9. (a) Depth profile of void ratio and (b) effective stress at 100 years of simulation for terrestrial depositions for tailings ponds of $5 \mathrm{~km}^{2}$ (solid line) and $10 \mathrm{~km}^{2}$ (dashed lines). [Colour online.]

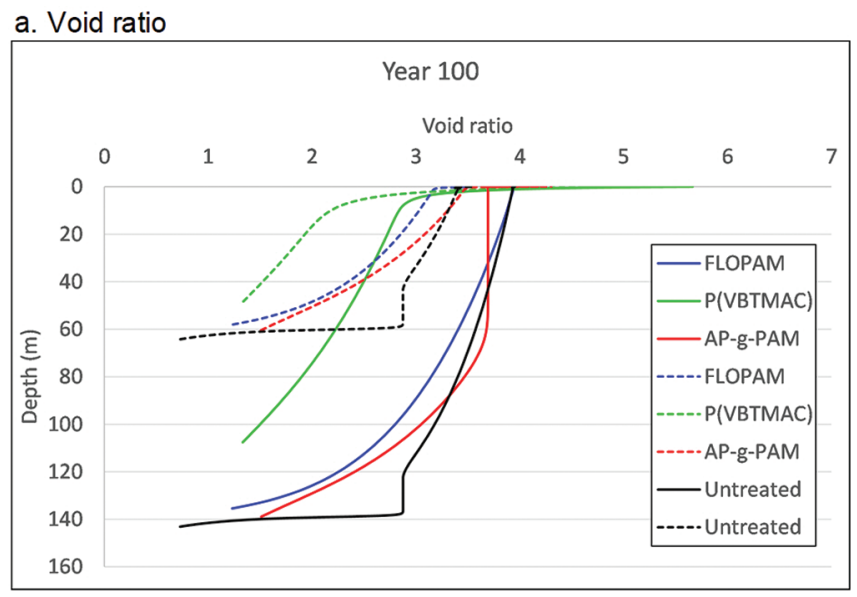

b. Effective stress

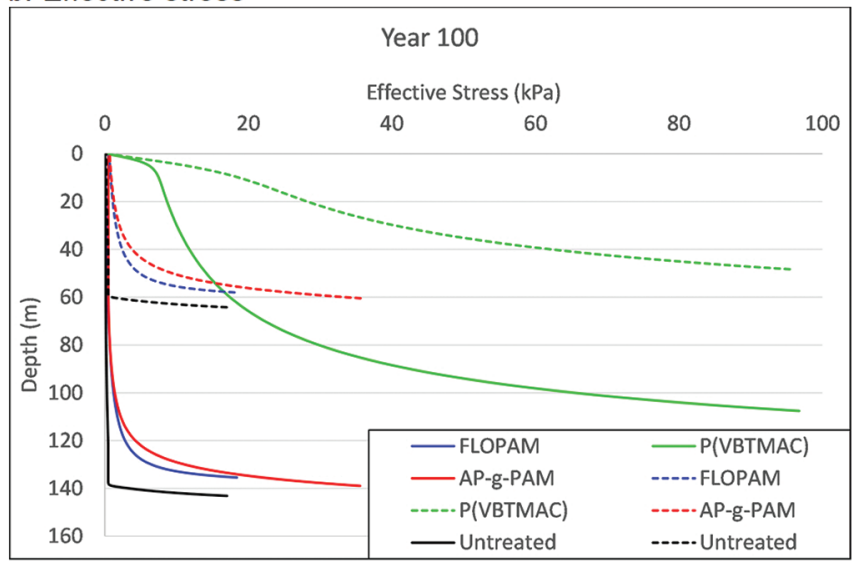

deposition for both tailings ponds compared to the other treated and untreated FFT (Fig. 8a). It should be noted that the initial height of the AP-g-PAM treated FFT is quite high due to its higher void ratio at deposition. This is stemming from the high polymer dosage requirements, which explains why the final height of the tailingswater interface is comparable to that of the other treated tailings, despite exhibiting the maximum overall settlement (Fig. 8b).

Variation of the top flux versus time shows that the AP-g-PAM treated FFT would have a minimum settlement rate at any time during quiescent conditions for the tailings pond of $5 \mathrm{~km}^{2}$, but the settlement rate of $\mathrm{P}(\mathrm{VBTMAC})$ treated $\mathrm{FFT}$ is minimum for the tailings pond of $10 \mathrm{~km}^{2}$ (Fig. $8 c$ ). Further, Figs. $8 b$ and $8 c$ show that both the settlement and top flux of AP-g-PAM treated FFT decrease rapidly during the initial 30 days while the settlement and top flux continue till 100 years of simulation for the FLOPAM and P(VBTMAC) treated FFT.

The void ratio and effective stress with depth at 100 years of the simulation (Fig. 9) are compatible with the above results. The $\mathrm{P}(\mathrm{VBTMAC})$ treated FFT show the minimum void ratio and the highest effective stress and shear strength in almost all depths. The AP-g-PAM treated FFT had the maximum void ratio, and the FLOPAM treated FFT have minimum effective stress, among other treatments for both hypothetical tailings ponds of $5 \mathrm{~km}^{2}$ (solid lines) and $10 \mathrm{~km}^{2}$ (dashed lines).

\section{Aquatic reclamation}

The results for the aquatic reclamation option are illustrated in Figs. 10 and 11. Figure $10 a$ shows that the P(VBTMAC) treated
FFT exhibit the lowest final height of the tailings-water interface compared to the other two treatments and untreated FFT at year 50 of the 5 and $10 \mathrm{~km}^{2}$ tailings pond simulation. However, at year 30 of the same simulation for the $10 \mathrm{~km}^{2}$ tailings pond, the AP-gPAM treated FFT exhibit the lowest tailings-water interface height. Figure $10 \mathrm{~b}$ shows that the AP-g-PAM treated FFT settle very rapidly in the first 100 days following the end of deposition. Moreover, the top flux (Fig. 10c) in the AP-g-PAM treated FFT deposit was the lowest in the post-deposition period and was about 2.5 times less than the other two polymer-treated and untreated FFT at year 50 of the simulation for both tailings ponds of 5 and $10 \mathrm{~km}^{2}$.

The void ratio and effective stress profiles with depth, illustrated in Fig. 11, show that the P(VBTMAC) treated FFT exhibit the lowest void ratio and highest effective stress throughout the 50 years of simulation for both tailings ponds of 5 and $10 \mathrm{~km}^{2}$. The AP-g-PAM treated FFT had a lower void ratio and higher effective stress compared to the FLOPAM treated and untreated FFT for the $5 \mathrm{~km}^{2}$ pond.

\section{Discussion}

Physio-geo-chemical processes occur simultaneously and can affect the interactions between the polymers and the FFT slurry. These interactions happen within the tailings matrix at both micro and macroscopic levels. The interplay at the microscopic level is unique to each polymer's ionic charge. Adsorption of the neutral polymer, AP-g-PAM, occurs through hydrogen bonding and Van der Waals forces. Conversely, the cationic polymer, $\mathrm{P}(\mathrm{VBTMAC})$, is held by electrostatic interactions between the positively charged monomeric units in the polymer chain and the negatively charged clay surfaces in the FFT slurry. Finally, anionic polyacrylamide, FLOPAM, interacts with the clay surface mainly through ion bridging on negatively charged clay surfaces with the help of divalent ions such as calcium or magnesium and (or) very high ionic strength cations such as sodium. Vajihinejad (2020) provided a detailed account of these chemical interactions. Furthermore, Amoako (2020) presented a comprehensive review of scanning electron microscopy (SEM) results. In these results, the untreated FFT exhibited a card-house microstructure formed by the edge-to-face association of dispersed clay minerals. The flocs form edge-to-edge and edge-to-face associations between clay mineral surfaces. Adding a neutral polymer, AP-g-PAM, resulted in mineral layering and face-to-face particle association, while edgeto-edge and edge-to-face association of clay mineral booklets at the nano- and microscales were observed in flocs made with the cationic, $\mathrm{P}(\mathrm{VBTMAC})$, and anionic, FLOPAM, flocculants.

On the macro scale, once these bonds were formed, the slurry particles agglomerated, as discussed in the particle-size distribution of each polymer treatment. The flocculated particles have larger sizes than the untreated specimen. According to Stoke's law, the larger particles settle faster, increasing the settling rate. Moreover, the resulting treatment's hydraulic conductivity is directly impacted by the particle-size distribution, which in turn governs the rate of consolidation.

In terms of the long-term performance, the trends shown in the consolidation modelling do, in fact, logically follow the measured properties in the LSC tests, as well as the primary polymer action expected from a chemistry perspective. An in-depth comparative analysis of the long-term performance of both new polymer treatments reveals that the AP-g-PAM treated FFT underperformed in all long-term simulations from a geotechnical perspective of strength and density relative to the $\mathrm{P}(\mathrm{VBTMAC})$ (Figs. 9 and 11). The reader is reminded that AP-g-PAM initially exhibited very rapid dewatering in the sedimentation tests. This signals that short-term dewatering tests may not necessarily lead to the same conclusions in the longterm and is, therefore, an important implication for the oil sands industry to consider. The high initial settlement followed by a slow 
Fig. 10. (a) Height of tailings-water interface versus time, $(b)$ settlement versus time, and $(c)$ top flux versus time for aquatic depositions for tailings ponds of $5 \mathrm{~km}^{2}$ (solid lines) and $10 \mathrm{~km}^{2}$ (dashed lines). [Colour online.]

a. Interface

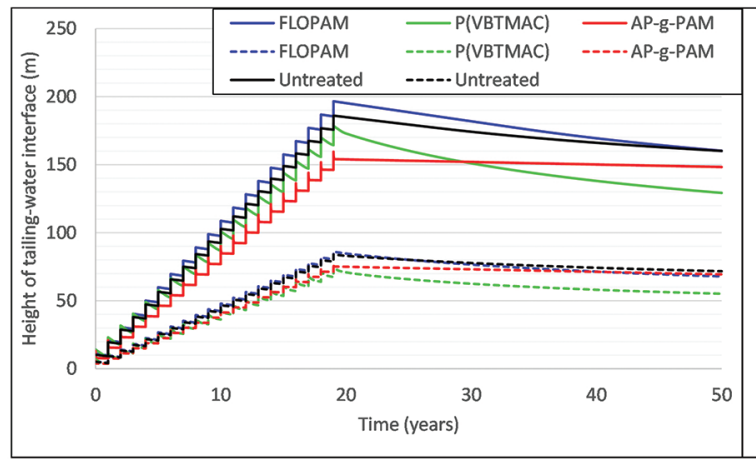

b. Settlement

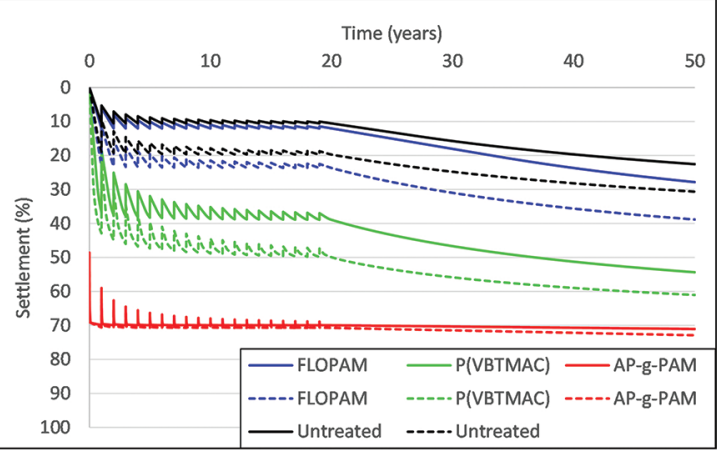

c. Top flux

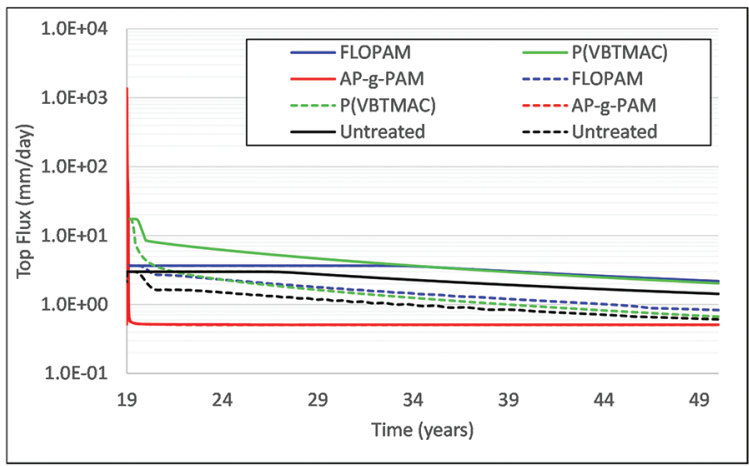

rate of consolidation compared to the other polymers (as seen in Fig. 8) can be directly linked to the measured hydraulic conductivity in the laboratory; where Fig. 4 shows that the AP-g-PAM treated FFT had the highest hydraulic conductivity for void ratios exceeding 5 yet the lowest hydraulic conductivity in the void ratio range of 2.5 to 4 . This is consistent with the observation that flocs formed by AP-g-PAM had a stiff branched structure that was susceptible to shear (Fig. 7).

P(VBTMAC) polymer outperformed both AP-g-PAM and FLOPAM in all long-term simulations from a geotechnical standpoint in terms of density and strength despite exhibiting the least shortterm dewatering prospect. This follows logically from the observation of higher hydraulic conductivity values at low void ratios (Fig. 5). Furthermore, it is consistent with its stable flocs matrix demonstrated both through the shear strength testing where the $S_{\mathrm{u}} / \sigma_{\mathrm{v}}^{\prime}$ ratio much less scatter (Fig. 6), and the lack of shear sensitivity during simulated pipeline transport in the Couette torque results further evidenced by low CST values even after considerable shearing (Fig. 7). P(VBTMAC) produces small silt-size flocs that are both resistant to inter-floc compression and retain high hydraulic conductivity at low void ratios. From all these findings, the superior long-term performance displayed in the modelling results seems quite plausible.

Therefore, the two proposed polymers each provide their unique benefits and shortcomings. The stability of the small flocs produced using the $\mathrm{P}(\mathrm{VBTMAC})$ polymer offers improved performance in terms of final deposit density and strength, while the AP-g-PAM polymer produces quick initial dewatering and less settlement in the long-term. This, in turn, translates into a minimal flux of potentially contaminated consolidation water rising to the surface. Hence a favourable option for aquatic landscape eventuality due to quicker ecosystem restoration. Conversely, the $\mathrm{P}(\mathrm{VBTMAC})$ polymer continues to settle over the long-term, releasing consolidation effluent toward the surface of the tailings deposit. Looking from a geotechnical lens, the strength and density associated with polymer P(VBTMAC) appeal to a terrestrial reclamation eventuality that may not be applicable for AP-g-PAM polymer given the considerably less dense and weaker deposits.

Based on these observations, the authors are pursuing targeted adjustments to the polymers. For the $\mathrm{P}(\mathrm{VBTMAC})$ polymer, the floc size can be increased by increasing the molecular weight of the linear polymer or by synthesizing a branched version of $\mathrm{P}(\mathrm{VBTMAC})$ without trading floc stability. This should increase the $k-e$ relationship to be somewhat higher, and therefore reduce the time over which substantial settlement in a deposit continues to occur. For both polymers, it may also be desirable to decrease the stiffness of individual flocs somewhat to improve their performance with respect to reducing retained water at a given level of stress. The floc compression can be adjusted by further modifying the relative hydrophobic/hydrophilic nature of the polymer, for instance, by copolymerizing VBTMAC with a more or less hydrophobic comonomer, while the amylopectin grafts can be rendered cationic by copolymerizing acrylamide and VBTMAC in different ratios (Vajihinejad et al. 2019).

The reader must bear in mind that these simulations are meant to be only comparative and are probably quite conservative with regards to real deposit performance. For example, considerably more dewatering would likely occur for terrestrial deposits due to evaporation and (or) freeze-thaw, based on experiences with operators' previous deposition of multilayer deposition at a commercial scale (Suncor's Tailings Reduction Operations, CNRL's Atmospheric Fines Drying trials). Similar inferences can be made based on experiments and modelling studies extrapolating available field data (Qi et al. 2017b; Simms et al. 2019; Qi and Simms 
Fig. 11. (a) Depth profiles of void ratio and (b) effective stress at 50 years of simulation for aquatic depositions for tailings ponds of $5 \mathrm{~km}^{2}$ (solid lines) and $10 \mathrm{~km}^{2}$ (dashed lines). [Colour online.]

a. Void ratio

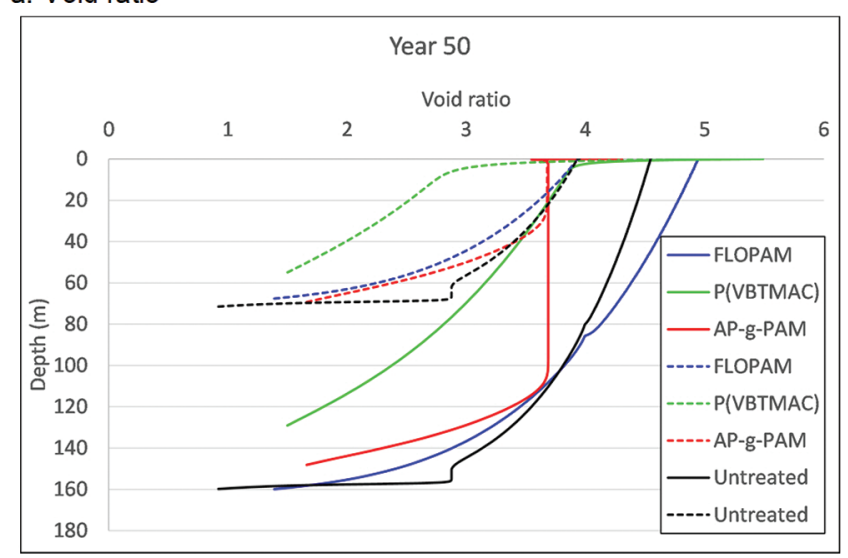

b. Effective stress

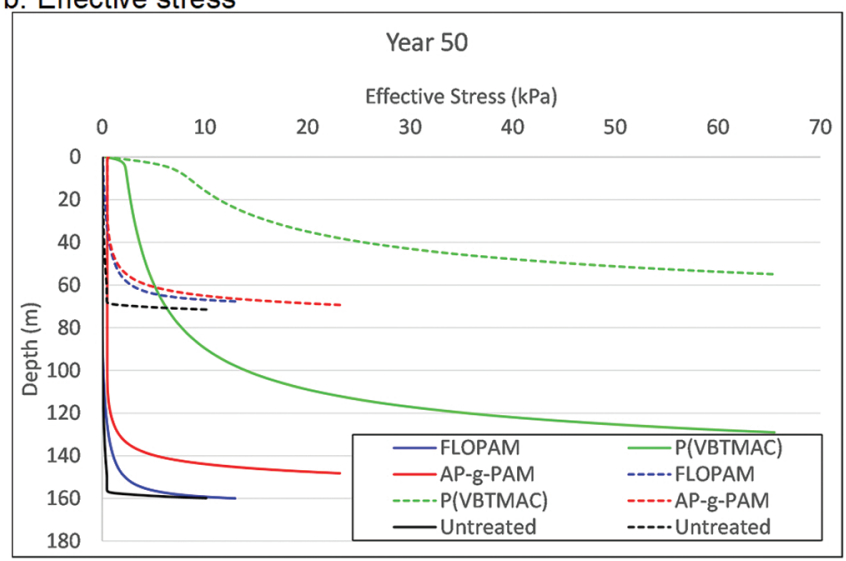

2018; Pham and Sego 2014; Proskin et al. 2012). Refinement of large strain consolidation predictions considering other phenomena such as creep/ageing (Jeeravipoolvarn 2010; Salam et al. 2018) continues to be investigated.

\section{Summary and conclusions}

The potential application of two new polymers was investigated as dewatering treatment of oil sands fluid fine tailings (FFT) deposits, one with a neutral ionic charge (AP-g-PAM) and the other cationic $(\mathrm{P}(\mathrm{VBTMAC}))$ polymer. Both polymers create very different tailings fabrics. The AP-g-PAM polymer undergoes quite remarkable dewatering at high void ratios and forms a branched polymer network; however, its permeability is lowest for the lower void ratios. The $\mathrm{P}(\mathrm{VBTMAC})$ polymer dewaters much less at higher void ratios, but forms silt-sized flocs that appear to be resistant to both shear during transport and do not collapse at high loads, giving the highest hydraulic conductivity at low void ratios. When the measured consolidation properties were incorporated into the analyses of hypothetical reclamation scenarios, it was evident that the $\mathrm{P}(\mathrm{VBTMAC})$ polymer developed the denser and stronger deposits under all scenarios.

In contrast, the AP-g-PAM treated FFT tailings produce less dense and weaker deposits, high initial settlement, with small residual/flux to the surface. This latter attribute of the AP-g-PAM polymer is favourable for aquatic deposition. The P(VBTMAC) polymer generates deposits that continue to settle at significant rates over decades: to improve performance in this regard, ongoing research is investigating increasing the floc size to increase the hydraulic conductivity further and so achieve more consolidation in the short-term as opposed to the long-term.

\section{Acknowledgements}

Financial support for this research was provided by the Natural Sciences and Engineering Research Council Collaborative Research and Development Grant 5000664-16 awarded to the last author, Paul Simms, in partnership with Canada's Oil Sands Innovation Alliance (COSIA) and co-principal investigators Nicholas Beier and Joao Soares. Thanks to Christine Hereygers of the University of Alberta for assisting with the laboratory program and to Muhammad Asif Salam of Carleton University for coordinating timely sample shipment.

\section{References}

Aldaeef, A.A., and Simms, P. 2019. Influence of pipeline transport on sedimentation and consolidation of flocculated Fluid Fine Tailings (fFFT). In Proceedings of the 72nd Canadian Geotechnical Conference, Canadian Geotechnical Society, St. John's, NL, Canada.

Amoako, K.A. 2020. Geotechnical behaviour of two novel polymer treatments of oil sands fine tailings. Masters of Science thesis, University of Alberta, Edmonton, Alta.

ASTM. 2007. Standard test method for particle-size analysis of soils. ASTM D422-63. ASTM International, West Conshohocken, Pa.

ASTM. 2016. Standard test methods for laboratory miniature vane shear test for saturated fine-grained clayey soil. ASTM D4648/D4648M. ASTM International, West Conshohocken, Pa., USA.

ASTM. 2017a. Standard test method for particle-size distribution (gradation) of fine-grained soils using the sedimentation (hydrometer) analysis. ASTM D7928. ASTM International, West Conshohocken, Pa., USA.

ASTM. 2017b. Standard test methods for liquid limit, plastic limit, and plasticity index of soils. ASTM D4318-17. ASTM International, West Conshohocken, Pa.

ASTM. 2019. Standard test method for permeability of granular soils (constant head). ASTM D2434. ASTM International, West Conshohocken, Pa., USA.

Bazoubandi, B., and Soares, J.B.P. 2020. Amylopectin-graft-polyacrylamide for the flocculation and dewatering of oil sands tailings wastewater. Minerals Engineering, 148: 106196. doi:10.1016/j.mineng.2020.106196.

Beier, N., Wilson, W., Dunmola, A., and Sego, D. 2013. Impact of flocculation-based dewatering on the shear strength of oil sands fine tailings. Canadian Geotechnical Journal, 50(9): 1001-1007. doi:10.1139/cgj-2012-0262.

CEMA. 2012. End pit lakes guidance document. Alberta Environment, Edmonton, Alberta.

COSIA. 2014. A guide to audit and assess oil sands fluid fine tailings performance management. Canada's Oil Sands Innovation Alliance (COSIA), Calgary. August 2014, $18 \mathrm{p}$.

Derakhshandeh, B., Junaid, A., and Freeman, G. 2016. Effects of shearing and shearing time on dewatering and yield characteristics of oil sands flocculated tailings. In Proceedings of the Fifth International Oil Sands Tailings Conference. pp. 416-421.

Elias, J.A. 2019. Measurement of floc size and the influence of size distribution on geotechnical properties of oil sands fluid fine tailings. Masters of Science thesis, University of Alberta, Edmonton, Alta.

Fox, P.J., and Berles, J.D. 1997. CS2: a piecewise-linear model for large strain consolidation. International Journal for Numerical and Analytical Methods in Geomechanics, 21(7): 453-475. doi:10.1002/(SICI)1096-9853(199707)21:7<453:: AID-NAG887>3.0.CO;2-B.

Gumfekar, S., Vajihinejad, V., and Soares, J.B.P. 2019. Advanced polymer flocculants for solid-liquid separation in oil sands tailings. Macromolecular Rapid Communications, 40: 1800644. doi:10.1002/marc.201800644.

Hripko, R., Vajihinejad, V., Motta, F.L., and Soares, J.B.P. 2018. Enhanced flocculation/dewatering of oil sands mature fine tailings by use of hydrophobically-modified polyacrylamide co-polymers. Global Challenges, 2: 1700135. doi:10.1002/gch2.201700135. PMID:31565327.

Jeeravipoolvarn, S. 2005. Compression behaviour of thixotropic oil sands tailings. Master's thesis, University of Alberta, Edmonton, Alberta.

Jeeravipoolvarn, S. 2010. Geotechnical behavior of in-line thickened oil sands tailings. Ph.D. thesis, University of Alberta, Edmonton, Alta.

Jeeravipoolvarn, S., Chalaturnyk, R.J., and Scott, J.D. 2009. Sedimentationconsolidation modeling with an interaction coefficient. Computers and Geotechnics, 36(5): 751-761. doi:10.1016/j.compgeo.2008.12.007.

Jeeravipoolvarn S., Masala, S., Zhang, C., and Moore, T. 2015. Revisiting the large strain consolidation test for oil sands. In Proceedings of Tailings and Mine Waste 2015, Vancouver, BC, 26-28 October 2015.

McKenna, G., Mooder, B., Burton, B., and Jamieson, A. 2016. Shear strength and density of oil sands fine tailings for reclamation to a boreal forest 
landscape. In Proceedings of the Fifth International Oil Sands Tailings Conference, 4-7 December 2016, Lake Louise, Alberta, Canada.

McKinley, J., Sellick, A., and Dawson, R. 2018. Fluid fine tailings management methods: an analysis of impacts on mine planning, land, GHGS, costs, site water balances and recycle water chloride concentrations. Report by Norwest Corporation to COSIA Project Number 799-3-4.

Mikula, R. 2018. The role of clays in the performance of oil-sands tailings management options. In Introduction to oil sands clays. Edited by D. Hockley and O. Omotoso. Clay Minerals Society, pp. 129-181.

Mikula, R., and Freeman, G. 2016. Chemical amendment of fluid fine tailings and related laboratory performance tests. In Proceedings of the Fifth International Oil Sands Tailings Conference, pp. 251-260.

Pham, N.H., and Sego, D.C. 2014. Modeling dewatering of oil sands mature fine tailings using freeze thaw. In Proceedings of the Fourth International Oil Sands Tailings Conference, 7-10 December 2014, Lake Louise, Alberta, Canada. Edited by C. David, G. Sego, W. Ward, and B. Nicholas. Department of Civil and Environmental Engineering, University of Alberta, Edmonton, Alberta. pp. 123-30.

Proskin, S.A., Sego, D.C., and Alostaz, M. 2010. Freeze-thaw and consolidation tests on Suncor Mature Fine Tailings (MFT). Cold Regions Science and Technology, 63(2010): 110-120. doi:10.1016/j.coldregions.2010.05.007.

Proskin, S., Sego, D.C., and Alostaz, M. 2012. Oil sands MFT properties and freeze-thaw effects. Journal of Cold Regions Engineering, 26(2): 29-54. doi:10.1061/(ASCE)CR.1943-5495.0000034.

Qi, S., and Simms, P. 2018. Hydro-mechanical coupling in dewatering simulations for mine tailings management. In Proceedings of the 7th International Conference on Unsaturated Soils. pp. 1157-1162.

Qi, S., Simms, P., and Vanapalli, S. 2017a. Piecewise-linear formulation of coupled large-strain consolidation and unsaturated flow. I: Model development and implementation. Journal of Geotechnical and Geoenvironmental Engineering, 143(7): 04017018. doi:10.1061/(ASCE)GT.1943-5606.0001657.

Qi, S., Simms, P., Vanapalli, S., and Soleimani, S. 2017b. Piecewise-linear formulation of coupled large-strain consolidation and unsaturated flow. II: Testing and performance. Journal of Geotechnical and Geoenvironmental Engineering, 143(7): 04017019. doi:10.1061/(ASCE)GT.1943-5606.0001658.

Qi, S., Simms, P., Daliri, F., and Vanapalli, S. 2020. Coupling elasto-plastic behaviour of unsaturated soils with piecewise linear large-strain consolidation. Géotechnique, 70(6): 518-537.
Royal Society of Canada Expert Panel. 2010. Executive Summary: Environmental and health impacts of Canada's oil sands industry rep. Royal Society of Canada, Ottawa, Ontario, Canada.

Salam, A.M. 2020. Effects of polymers on short- and long-term dewatering of oil sands tailings. Ph.D. thesis, Environmental Engineering, Carleton University, Ottawa, Ontario, Canada.

Salam, A.M., Simms, P.H., and Örmeci, B. 2018. Evidence of creep \& structuration in polymer amended oil sands tailings. In Proceedings of the 6th International Oil Sands Tailings Conference. Edmonton, Alberta.

Sawatsky, L., Hyndman, A., and McKenna, G. 2018. Fluid fine tailings processes: disposal, capping, and closure alternatives. In Proceedings of the Sixth International Oil Sands Tailings Conference, Edmonton, Alberta.

Simms, P., Soleimani, S., Mizani, S., Daliri, F., Dunmola, A., Rozina, E., and Innocent-Bernard, T. 2019. Cracking, salinity and evaporation in mesoscale experiments on three types of tailings. Environmental Geotechnics, 6(1): 3-17. doi:10.1680/jenge.16.00026.

Suthaker, N.N., and Scott, J.D. 1997. Thixotropic strength measurement of oil sand fine tailings. Canadian Geotechnical Journal, 34(6): 974-984. doi:10.1139/t97-064.

Vajihinejad, V. 2020 Polymer treatment of oil sands tailings: experimental and modeling investigations. Ph.D. thesis, University of Alberta.

Vajihinejad, V., Gumfekar, S.P., Bazoubandi, B., Najafabadi, Z.R., and Soares, J.B.P. 2019. Water soluble polymer flocculants: synthesis, characterization and performance assessment. Macromolecular Materials and Engineering, 304: 1800526. doi:10.1002/mame.201800526.

Vandara, K. 2018. Polymer assessment on dewatering of oil sands tailings. Master of Engineering report, Carleton University, Ottawa, Ontario.

Vietti, A. 2018. Clay-water interactions. In Introduction to oil sands clays. Edited by D. Hockley and O. Omotoso. Clay Minerals Society. pp. 61-74.

Wilson, G.W., Kabwe, L.K., Beier, N.A., and Scott, J.D. 2018. Effect of various treatments on consolidation of oil sands fluid fine tailings. Canadian Geotechnical Journal, 55(8): 1059-1066. doi:10.1139/cgj-2017-0268.

Yao, Y., van Tol, A.F., and van Paassen, L. 2012. The effect of flocculant on the geotechnical properties of mature fine tailings: An experimental study. In Proceedings of the Third International Oil Sands Tailings Conference, Edmonton, Alberta. pp. 391-398.

Znidarčić, D., Van Zyl, D., Ramirez, M., Mittal, K., and Kaminsky, H. 2016. Consolidation characteristics of flocculated MFT - Experimental column and SICT data. In Proceedings of the Fifth International Oil Sands Tailings Conference, Lake Louise, University of Alberta, Edmonton, Alberta. pp. 408-415. 